\title{
The Semantic Error Problem for Epistemic Contextualism
}

\author{
Patrick Greenough \& Dirk Kindermann \\ Forthcoming in Routledge Handbook of Epistemic Contextualism \\ edited by Jonathan Jenkins-Ichikawa \\ Penultimate Draft
}

\section{Introduction}

Epistemic Contextualism is the view that "knows that" is semantically context-sensitive and that properly accommodating this fact into our philosophical theory promises to solve various puzzles concerning knowledge. ${ }^{1}$ Yet Epistemic Contextualism faces a big-some would say fatal-problem: The Semantic Error Problem. ${ }^{2}$ In its prominent form, this runs thus: speakers just don't seem to recognise that "knows that" is context-sensitive; so, if "knows that" really is context-sensitive then such speakers are systematically in error about what is said by, or how to evaluate, ordinary uses of "S knows that $p$ "; but since it's wildly implausible that ordinary speakers should exhibit such systematic error, the expression "knows that" isn't context-sensitive. ${ }^{3}$

We are interested in whether, and in what ways, there is such semantic error; if there is such error, how it arises and is made manifest; and, again, if there is such error to what extent it is a problem for Epistemic Contextualism. The upshot is that some forms of The Semantic Error Problem turn out to be largely unproblematic. Those that remain troublesome have analogue error problems for various competitor conceptions of knowledge. So, if error is any sort of problem, then there is a problem for every extant competitor view.

\section{Epistemic Contextualism}

Broadly conceived, Epistemic Contextualism (hereafter: Contextualism) is the view that the truth-value of "S knows that $p$ " is sensitive to the epistemic standards which obtain in the context of use. ${ }^{4}$ These standards fix how strong the epistemic position of the subject $\mathrm{S}$ needs to be in order for this sentence to be true. So, in some context, a speaker may truly utter "S knows that $p$ ", while in a different context, a speaker may truly utter "S does not know that $p$ ", even though these contexts merely differ in respect of the epistemic standards-and so remain the same in respect of epistemic position. 
Specific forms of Contextualism differ as to what this sameness of epistemic position amounts to. For convenience, we assume it amounts to the sameness of the evidence of the subject S. ${ }^{5}$ Furthermore, there are various accounts as to what raises or lowers the epistemic standards. For simplicity, we assume the standards are fixed by which error possibilities are salient (ignoring, e.g., practical stakes). We shall also assume that there are just two contexts: high standards contexts, (hereafter: HIGH), where even far-fetched error possibilities are salient; and low-standards contexts, (hereafter: LOW), where such error possibilities are not salient. Any differences between this simplified version and specific contemporary forms of Contextualism shouldn't matter to our discussion.

\section{Modest versus Ambitious Contextualism}

Modest Contextualism merely gives a theory of the meaning and use of "S knows that $p$ " and thus involves: accounting for the intuitive judgements concerning the truth, or assertibility, of this sentence; making sense of (dis)agreement involving such sentences; and specifying the norms of assertion and retraction for such sentences. Ambitious Contextualism, meanwhile, deploys the insights gained from Modest Contextualism to resolve a range of puzzles concerning knowledge, such as Cartesian Scepticism, lottery scepticism, the dogmatism paradox, the puzzle of easy knowledge, and so on. As we shall see, semantic error problems have been leveled against both kinds of Contextualist project. ${ }^{6}$

\section{Kinds of Semantic Error: Preliminary Distinctions}

Broadly, semantic error is some kind of mistake, made by a speaker, with respect to some semantic property of a word or string of words. A prototypical case is where a speaker is mistaken about what a word means. Such a mistake, we assume, typically comes with some false, usually implicit, belief, and typically manifests itself by some mistaken (potential) use of the word. Semantic error can be a mistake about a semantic feature that is in principle accessible to ordinary speakers or about an elusive semantic feature which only a theorist of language may be privy to. To isolate the relevant kinds of error we are interested in, it will help to sketch some preliminary distinctions: 
(1) Semantic Error versus Semantic Ignorance: Semantic error involves more than mere ignorance; it typically involves some false (implicit) belief about some semantic property of an expression. ${ }^{7}$ Such a false (implicit) belief will typically be made manifest by some misuse of the expression in question.

(2) Global versus Local Semantic Error: A speaker makes a local semantic error if she uses the word in ways incompatible with the semantic theory only in specific kinds of use situation (such as the sceptical argument); a speaker makes a global semantic error if she uses the word in ways incompatible with the semantic theory in all kinds of use situations.

(3) Universal versus Individual Semantic Error: Semantic error is universal (with respect to a language community) if all (or nearly all) competent speakers of that language community are in error. It is individual (with respect to a language community) if it occurs only in a single competent speaker of the language.

(4) Systematic vs Non-Systematic Semantic Error: Given a particular kind of use situation (e.g. the sceptical argument), a speaker who always uses the expression in a particular, erroneous way is systematically semantically in error. One who does so only in some instantiations of a given kind of use situation is non-systematically in error. ${ }^{8}$

As we shall see, Contextualism is allegedly committed to positing a kind of semantic error which is systematic, universal, and multiply local.

\section{Ambitious Contextualism and Cartesian Scepticism}

Ambitious Contextualism, as mentioned above seeks to resolve various epistemological puzzles. With respect to Cartesian Scepticism, it typically proceeds as follows:

(i) The basic form of the (Cartesian) Sceptical Argument (SA) is this:

Premise A: I don't know that not-SH.

Premise B: If I don't know that not-SH then I don't know that 0.

Conclusion C: $\quad$ I don't know that $0 .{ }^{9}$ 
Here 0 stands for some ordinary claim (e.g. I am in London), and SH for some sceptical hypothesis (e.g. I am a brain in a vat being "fed" non-veridical experiences of the external world).

(ii) SA represents a paradox: the premises A and B are (initially) highly plausible; the conclusion $\mathrm{C}$ is (initially) highly implausible; yet, the reasoning from A and B to C is (taken to be) valid.

Standardly, to resolve a paradox one must discharge two explanatory tasks: (1) Establish some fault with the reasoning, premises, or presuppositions of the argument, or establish that the conclusion is not so toxic after all. (2) Explain just why we, epistemologists and the folk alike, mistakenly thought that some premise, rule of inference, or presupposition was true/valid, or explain why, contra initial appearances, the conclusion is not so toxic after all.

To discharge the first explanatory task, Ambitious Contextualism proceeds thus:

(iii) Premise A introduces a sceptical hypothesis thus raising the standards to HIGH. A is true in HIGH because my epistemic position is too weak to meet the standards for "I know that not-SH" to be true.10

(iv) Premise B is true as used in both LOW and HIGH.11

(v) So, for Ambitious Contextualism, SA turns out to be a sound argument at least in HIGH: the premises $\mathrm{A}$ and $\mathrm{B}$, used in $\mathrm{HIGH}$, are both true, the reasoning is deductively valid, and so the conclusion $\mathrm{C}$, as derived in HIGH, is true too.

(vi) In contrast, the conclusion $\mathrm{C}$ is false when used in LOW. That's because when sceptical error possibilities are not salient, my epistemic position is strong enough to meet the epistemic standards.

(vii) For Ambitious Contextualism, the upshot of (v) and (vi) is that although the sceptical argument does indeed show that knowledge ascriptions turn out to be false when used in HIGH, it falls short of establishing that ordinary knowledge ascriptions are false when used in LOW. Thus, the sting of SA has, allegedly, been drawn because it fails to establish tout court that I lack knowledge of ordinary propositions. ${ }^{12}$ 


\section{Local and Global Semantic Error}

What of the second task? This amounts to explaining why we (initially) take $\mathrm{C}$ to be false, despite the fact that, as used in SA, it is true. Contextualism's explanation is as follows:

(viii) Despite its use in SA, we mistakenly treat the conclusion C as if it was used in LOW, and thus we treat it as expressing the false proposition it would express in LOW. Furthermore, we are unaware of our assessing, when considering SA, this false proposition rather than the true proposition C expresses in the HIGH context of SA. This explains why we (initially) find C so implausible despite the fact that it straightforwardly follows from plausible premises. ${ }^{13}$

So, if SA is a paradox, with initially plausible premises and a (simultaneously) implausible conclusion, then, according to Ambitious Contextualism, the speaker of SA makes a certain Local Semantic Error:

Local Semantic Error: The speaker of SA mistakenly takes C, when derived in SA, as saying something false.

In a much discussed paper, in which the Semantic Error Problem first rose to prominence, Schiffer (1996) offers an explanation of the source of this Local Semantic Error:

[SA] strikes us as presenting a profound paradox merely because we're ignorant of what it's really saying, and this because we don't appreciate the indexical nature of knowledge sentences (Schiffer 1996, p. 325).

Here, Schiffer has a specific version of Contextualism in mind, namely, Indexical Contextualism, according to which utterances of "S knows that p" can express different propositions in contexts where the epistemic standards differ (see below).

With the help of our distinctions from $§ 4$, we reconstruct Schiffer's reasoning as follows: Firstly, we have:

Global Indexical Ignorance: The speaker of "S knows that $p$ " is ignorant of the fact that this sentence can say different things in different contexts of use (which merely differ with respect to the epistemic standards). 
Since such ignorance of indexicality will, plausibly, lead the speaker to treat "S knows that p" as having an invariant content (across contexts which merely differ with respect to the epistemic standards), we then have:

Global Indexical Error: The speaker mistakenly takes "S knows that $p$ " to say the same thing across these contexts.

Furthermore, if we assume, for the time being, that the relevant context-sensitivity is exhausted by indexicality, then we can derive the more generic error claim:

Global Context-Sensitivity Error: The speaker mistakenly takes "S knows that $p$ " to have the same truth-value across contexts (which merely differ with respect to the epistemic standards).

Given this, and the fact that the speaker takes "S does not know that $\mathrm{O}$ ", as used in ordinary contexts, to be false, the Local Semantic Error immediately follows: the speaker mistakenly takes C, when used/derived in SA, to be false.

\section{The Semantic Error Problem for Ambitious Contextualism}

Does this pose a serious problem for Ambitious Contextualism? Schiffer thinks so: "while this error theory is an inevitable corollary of the semantics the Contextualist needs to sustain her solution to Cartesian Scepticism, it's a pretty lame account of how, according to her, we came to be bamboozled by our own words" (p. 329). Why exactly? Schiffer says:

Since a knowledge sentence is supposed to express different propositions in different contexts even if it contains no apparently indexical terms, one naturally thinks of a "hidden-indexical" theory of knowledge sentences [...] What's hard to see is how the hidden-indexical proposal can sustain the idea that fluent speakers systematically confound their contexts, so that even when they're in a context in which [HIGH] is the induced standard occurring in the false proposition they have just asserted, they mistakenly think they've just asserted a true proposition, a proposition that evidently contains the standard [LOW] that would be induced by an utterance 
of the problematic sentence in a quite different context. It's as though a fluent, sane, and alert speaker, who knows where she is, were actually to assert the proposition that it's raining in London when she mistakenly thinks she's asserting the proposition that it's raining in Oxford. Actually, the situation is even much more problematic. For the speaker would not only have to be confounding the proposition she's saying; she'd also have to be totally ignorant of the sort of thing she's saying (Schiffer 1996, p. 326).

Moreover, Schiffer thinks that attribution of Global Indexical Ignorance and, in turn, Error is independently needed by the Contextualist because

[...] no ordinary person who utters 'I know that p', however articulate, would dream of telling you that what he meant and was implicitly stating was that he knew that $\mathrm{p}$ relative to such-andsuch standard (p. 326).

And so, if "knows that" is an indexical, this person is not only wrong about what particular proposition is being expressed, but ignorant of the very kind of proposition being expressed. That's why they mistakenly take "S knows that $p$ " to express the same proposition across all contexts. ${ }^{14}$

Schiffer concludes that the kind of error attribution needed by Indexical Contextualism is "extreme" and "has no plausibility: speakers would know what they were saying if knowledge sentences were indexical in the way the Contextualist requires" (p. 328). In effect, Schiffer is making the claim that the required error attribution is highly implausible because the kind of Global Indexical Ignorance/Error he thinks is needed to explain the Local Semantic Error would represent a hitherto unprecedented form of semantic error that no other indexical words exhibit-the error attribution would be just too ad hoc to be taken seriously.

\section{Schiffer's Local Semantic Error Objection Regimented}

A regimentation of Schiffer's Local Semantic Error Objection against Ambitious Contextualism thus runs:

(1) The Sceptical Argument SA is a paradox with plausible premises, A and B, and an implausible conclusion $\mathrm{C}$. 
(2) Ambitious Contextualism entails that SA is in fact sound-at least when run in HIGH.

(3) So according to Ambitious Contextualism, the conclusion of SA is non-toxic because it falls short of establishing that ordinary standards for knowledge are not met.

(4) However, Ambitious Contextualism also needs to explain why we were drawn into the paradox in the first place and, in particular, explain why we took the conclusion to be so implausible.

(5) Contextualism can do this only if it posits that the speaker of SA is making a Local Semantic Error whereby they mistakenly take $C$, when derived in SA, as saying something false.

(6) Such a Local Semantic Error is only to be explained via positing a kind of Global Indexical Error whereby the speaker does not appreciate the indexical nature of "knows that" and so mistakenly treats $\mathrm{C}$, when derived in SA, as expressing the same proposition it expresses when used outside of the sceptical argument.

(7) But Global Indexical Error represents a hitherto unprecedented form of error that no other indexical words exhibit.

(8) Hence, attribution of such error is implausible.

(9) There is no other theory of context-sensitivity which can be appealed to which can explain the Local Semantic Error.

(10) Thus, there is no plausible Contextualist response to SA.

How should Contextualism respond?

\section{Two Initial Responses \\ 9.1 Response One: Get used to it!}

One immediate response is to concede that the requisite global error is indeed unprecedented but deny this makes the required error attribution implausible. So, reject the move from (7) to (8) in the Local Semantic Error Objection above. One way to do this is to reason as follows. ${ }^{15}$ There is substantial and reasonably stable disagreement amongst competent users of "knows that" as to whether premise A of SA is true. If moderate invariantism is true then premise A, as used in SA, is false.16 If (scepticismfriendly) Contextualism is true then Premise A, as used in SA, is true. Either way, a large number of competent speakers are in error as to the truth-value of premise A-at least as used in SA. So, either way, an error theory is needed. However, as DeRose puts it, 
there may be some reason for thinking it's more problematic to suppose that many speakers are blind to the context-sensitivity of their own words than to suppose that many are blind to the context-insensitivity of their own words. But it's not easy to see how to give any credible argument for such an asymmetry and it's perhaps best not to stretch to anticipate how such an argument might go (DeRose 2006, p. 335, emphasis in original).

The upshot is that while Contextualism does indeed require an unprecedented error attribution this does not make this error attribution implausible all things considered, because it will be no more implausible than the unprecedented error theory needed by competing invariantist theories of knowledge.

This response is plausible to the degree to which its pessimism is warranted. Is there no good way to "stretch" and argue for the superiority of an error attribution for invariantism, or for Contextualism? Work published around the time and after DeRose's pessimistic response gives reason to believe that a more sophisticated weighing of pros and cons is possible, once the views' profile of error attributions and, hence, need for an error theory, comes into sharper relief.17

\subsection{Response Two: Favor Modest over Ambitious Contextualism}

A second initial response concedes that Schiffer's Local Semantic Error Objection is effective against a Contextualist of treatment of SA, but maintain this just shows that Modest should be preferred over Ambitious Contextualism.

Firstly, such a response robs Contextualism of much of its philosophical interest since it is not equipped to address Cartesian Scepticism (and related puzzles). Secondly, and more tellingly, Modest Contextualism is still subject to a Global Semantic Error Objection which is effectively embedded in the Local Semantic Error Objection given above. Let's now see why this is so.

\section{Schiffer's Global Semantic Error Objection}

It's worth distinguishing a crude from a more sophisticated form of the Global Semantic Error Objection. The crude form runs as follows: indexicality should be obvious; since "knows that" is not 
obviously indexical, it's not indexical. The underlying idea is semantic transparency: if speakers, in their linguistic behavior, are unaware of some putative feature of meaning, then the feature does not exist. On this view, there is just no room for Indexical Semantic Error. But semantic transparency is implausible. As Schaffer \& Szabo $(2014,534)$ put it: "Virtually every sophisticated semantic theory posits all sorts of non-transparent features. Non-obvious context sensitivity is just more of the same."18 The more sophisticated form of the objection, encountered briefly above, proceeds as follows:

(1) "Knows that" is a standard kind of indexical (either an indexical verb or a hidden indexical or some other familiar kind of indexical).

(2) If "knows that" is a standard indexical then competent users should be able to recognise this.

(3) Such users are in a position to recognise this only if they are able to articulate or clarify the proposition that gets expressed by "S knows that p" (in some context of use).

(4) But competent users are not typically able to articulate or clarify the proposition that gets expressed.

(5) So, "knows that" is not a standard kind of indexical.

(6) So, if "knows that" is an indexical, its indexicality is unprecedented.

(7) But such unprecedented indexicality is just ad hoc and thus "has no plausibility".19

In effect, Schiffer presumes that a speaker who is semantically competent with regard to the class of indexical expressions in question satisfies something like the following thesis:

Content Articulation Thesis: Semantic competence with regard to an indexical sentence S requires that speakers be able to specify what is said by $S$ (in some context c) by articulating a natural language sentence that literally expresses the proposition originally asserted (in c).

\section{An Initial Response to the Global Semantic Error Objection}

An initial response is that the Content Articulation Thesis is too demanding. Competent speakers do not generally have to be able to articulate semantic content when using context-sensitive expressions. For instance, articulating the contextually determined modal base of a modal auxiliary like "might" —as is done, e.g., by expressions like "in view of my/x's current information" or "in view of orthodox 
Christian moral principles"-is not always something competent speakers can do. Similarly, articulating a token quantifier's restricted domain (as in "in this apartment", "among the students in this class") can be difficult. Moreover, even a speaker who says "It's raining" (Schiffer's example) and responds to repeated requests regarding what she meant that what she meant is just that it is raining can count as a competent speaker. She may not be particularly attuned to differences between what she said (the words she used) and what meaning she expressed, and she may not be sensitive to the interpretive needs of her hearer, but this by itself does not show she is not competent. Examples like these are legion.

\section{The Global Semantic Error Objection Strengthened}

Even if the Content Articulation Thesis is too strong, Schiffer's objection can be modified thus: if "knows that" is context-sensitive in the way gradable adjectives or "hidden indexicals" are (substitute a given Contextualist's favorite model of context-sensitivity), then how come speakers are much better at clarifying what they meant using gradable adjectives etc. than they are with knowledge ascriptions? How come they have prepositional phrases such as "in London" for the articulation of location or "for a basketball player" for the articulation of a comparison class to a use of "tall" more readily at hand than they have any phrases articulating epistemic standards? Note this challenge does not rely on the Content Articulation Thesis, merely on the difference between the ease of articulation with "knows" and paradigmatic examples of the Contextualist's favorite model of context-sensitive expressions (cf. Hawthorne 2004, 104-5).

\section{Responding to the Strengthened Global Semantic Error Objection}

Contextualists can meet this challenge in two ways. First, they can point to semantic or non-semantic features that plausibly distinguish "knows that" and knowledge from the relevant context-sensitive model expressions and their subject matters. Thus, Blome-Tillmann (2014, section 4.4) explains our lesser propensity to clarify knowledge ascriptions by the dependence of knowledge claims' felicity on the pragmatic presuppositions of the original context of utterance and the fact that a speaker's clarification would involve conceding that the presuppositions that are needed to render her original knowledge ascription true were absent, thereby making clarification "pragmatically incoherent." A 
parallel dependence on pragmatic presuppositions is not systematically present with uses of gradable adjectives.

Cohen, relatedly, observes that, more generally, semantic ignorance with context-sensitive expressions comes in degrees. (His response is not targeting content articulation in particular.) He explains our high degree of ignorance with respect to "knows" by pointing out that knowledge is a normative concept; possession of knowledge is valuable. Hence, Contextualism's "good news" is that we can ascribe a lot of that valuable good (in everyday contexts). The "bad news" is that we nevertheless don't always meet the highest epistemic standards. A similar "good news, bad news" Contextualist account holds for gradable adjectives like "flat." The difference in semantic ignorance between "flat" and "knows" is due to the fact that "we find [the bad news] much easier to accept in the case of flatness than knowledge, because ascriptions of flatness do not have the normative force that ascriptions of knowledge/justification do." (Cohen 2004, 192f.; 2005, 61f.; cf. also Neta 2003, 407-9)

Second, Contextualists can also meet the articulation challenge by denying any relevant differences in articulatory ability. Thus, Schaffer \& Szabo (2014), for instance, could respond-in line with their response to another strand of the semantic error objection-that speakers are not worse in articulating the content of knowledge ascriptions than they are with other relevant context-sensitive expressions: A-quantifiers such as the adverb "always" or modal auxiliaries might, can, must. The asymmetries only show that "knows" is not like gradable adjectives or "hidden indexicals" in its context-sensitivity.

This latter response is a special instance of a popular Contextualist strategy to argue that the attributed error is not ad hoc-pace step (7) in the Schiffer's Global Semantic Error Objection (section 10)-since similar error patterns can be found with the (particular Contextualist's chosen) analogous class of context-sensitive terms (whether or not the error is just as grave as with "knows"). For instance, Cohen (1999, 77-9) argues that while speakers are prone to ascribing flatness to paradigmatic tables, they may be led to deny that some paradigmatic table is flat in the context of setting up a sensitive scientific experiment, when microscopic bumps in the table's surface are salient. Moreover, they take their denial to be in conflict with their previous lenient ascription of flatness to the same table. But since there is, just like for "knows", strong evidence in favour of the context-sensitivity of gradable adjectives like "tall", it is plausible to assume that speakers are simply unaware of the context-sensitivity of "tall" and thus mistakenly withdraw their flatness ascription in light of raised standards. Indexical Error is thus argued to be well-attested with other kinds of expression that are context-sensitive in ways similar to "knows" (cf. also Blome-Tillmann 2008; 2014, section 4.1; Cohen 2004; 2005, 60f.; DeRose 2006, 327-31; 2009, 168-74). 
The force of this response depends on the independent evidence there is in favor of a Contextualist semantics of the model context-sensitive expression (gradable adjectives, quantified noun phrases, adverbial quantifiers, modal auxiliaries, ...) and also largely on intuitive judgments: Do the Contextualist's particular model context-sensitive expression in fact have use patterns relevantly similar to knowledge claims, or do their use patterns not require a Contextualist error attribution? To our knowledge, this question still awaits empirical testing.

\section{The Self-Undermining Objection}

Our discussion so far revolved around Schiffer's original error case(s) against Contextualism, as it already prefigures most of the strands of error objections levelled against Contextualism. But there is a yet another dimension along which Indexical Error may be thought to be worrisome. MacFarlane (2005) gives expression to this worry when he claims that there is a general problem with attributing (semantic) error to competent speakers:

[A] general problem with positing speaker error to explain away facts about use is that such explanations tend to undermine the evidential basis for the semantic theories [Contextualism, moderate and strict invariantism, subject-sensitive invariantism] they are intended to support. All of these semantic theories are justified indirectly on the basis of facts about speakers' use of sentences, and the more error we attribute to speakers, the less we can conclude from these facts. ${ }^{20}$

MacFarlane makes this dialectical point after having argued that all the mentioned theories face commitment to some error attribution or other. For instance, according to MacFarlane, Contextualists make the wrong predictions about speakers' cross-contextual truth ascriptions to knowledge ascriptions and their willingness to retract. Thus, suppose Cem asserts "I know that my car is parked in the driveway" and is subsequently presented with error possibilities to the effect that car thieves are often nearby. This is likely to raise the epistemic standards, and Cem is now inclined to say that his assertion in the previous context was false. Moreover, MacFarlane claims, Cem will treat it as false: if challenged, he will retract his earlier knowledge claim, e.g. by saying "I was wrong. I take that back. I didn't know my car is parked in the driveway" (cf. also Hawthorne 2004, 163; Williamson 2005, 220).

There are two ways in which error attributions may be considered generally troublesome: 
(1) The "double-edged sword" (MacFarlane 2005, 213-216). A particular error that explains the use facts that are troubling one view may equally explain other use facts that are troubling another view. For instance, Contextualists' attribution of error to explain cross-contextual truth ascriptions and retraction data runs the risk of equally explaining the data that Contextualists may use in their case against other views. If the involved error is one of projecting the relevant features of one's own context of use onto other contexts of use, subject-sensitive, or interest-relative, invariantists (Hawthorne 2004, Stanley 2005, Fantl \& McGrath 2009) may use this sort of projection error to explain why speakers do not treat temporal and modal operators as shifting epistemic standards, e.g., in "Before you mentioned car thieves' roaming the neighbourhood, I did know that my car is parked in the driveway" - use facts that are not predicted by subject-sensitive invariantist semantics. Attributions of semantic error may end up levelling the dialectical playing field.

(2) Overgeneration. Explaining a given set of data by attributing error risks overgeneration: other data that proponents of a view claim support their view may also be explained by the attributed error, thus undermining the evidential basis for the view. ${ }^{21}$

\section{Responding to the Self-Undermining Objection}

Self-undermining objections can be understood as challenges to the semantic view rather than knockdown objections. As it stands, many error attributions are mere diagnoses of the ways in which speakers diverge from the alleged 'correct' use of "knows". There are some attempts to meet this challenge by providing more specific psychological error theories-theories that explain the error by appeal to some general psychological phenomena rather than merely call some use facts erroneous. Both the dialectical double-edged sword and the overgeneration problems can be defused for a particular semantics if a specific error theory can be shown to explain all and only those use facts which it is needed to explain. That is, it may be shown that the error theory doesn't explain further use facts that allegedly support the semantics (defusing overgeneration worries), and that it cannot be coopted by rival semantic theories to explain their own troubling use facts (defusing the double-edged sword worry). See $§ 18$.

Our discussion so far focused on the varieties of error objections levelled against Contextualism and the responses available to Contextualists. We have not specifically addressed versions of these objections based on further kinds of data: cross-contextual judgments about the truth/acceptability of knowledge ascriptions and retraction (e.g. Hawthorne 2004, MacFarlane 2005, Stanley 2005, 
Williamson 2005); agreement and disagreement (e.g. see also chapter 20, "The Disagreement Challenge to Contextualism"). Contextualism, however, isn't the only view suffering from error objections. A full appreciation of the force of Contextualism's error objections requires taking into account the proliferation of error objections in the debate on knowledge ascriptions. In what follows, we illustrate two of the ways in which error objections multiply in the debate on knowledge ascriptions: as objections against relativism (§16) and against moderate invariantists who supplement their invariant semantics with a variable pragmatics $(\S 17)$.

\section{Generalizing the Challenge: Relativism's Index Error}

A basic point in favor of Contextualism is the variability in speakers' acceptance, or rejection, of knowledge ascriptions depending on the context they are in. Classical invariantists have trouble accounting for this contextual variability. They, too, appear to be in need of error attributions to ordinary speakers (cf. §9.1) - or of some other way to account for contextual variability (cf. §17). MacFarlane (2005) extends this point to further views. The upshot in his paper is that while all major non-relativist views are stuck with some problematic error attributions (or worse options), his assessment-sensitive, relativist semantics of knowledge ascriptions is error attribution-free and should be preferred on these grounds.

In response, Montminy (2009) and Kindermann (2013) have argued that relativism about knowledge ascriptions faces its own semantic error objections. ${ }^{22}$ Assessment-sensitive relativism about knowledge ascription is, very roughly, the view that while a given instance of "S knows [doesn't know] that p" expresses the same content across different contexts of use, this content may vary in truth value with the epistemic standards operative in different contexts of assessment. ${ }^{23}$ Kindermann (2013) objects that relativism faces a version of Schiffer's objection: A satisfactory relativist solution to the sceptical paradox must explain the appearance of paradox by appeal to an attribution of semantic error to assessors. However, the kind of error relativists need to ascribe differs from Indexical Error, which Contextualists must ascribe (see section 6). ${ }^{24}$ For relativists, however, "knows" does not induce the expression of different contents at different contexts of utterance. In contrast, a content expressed by a given knowledge sentence may be true at one assessor's circumstances of evaluation - or "index" and false at another assessor's index. As a result, the kind of ignorance relativists must attribute to assessors is "Index Ignorance": 
Index Ignorance: Speakers are ignorant of the fact that the truth value of contents expressed by sentences of the form "S knows [doesn't know] that p" can vary with the epistemic standards in the index..$^{25}$

But Index Ignorance, the objection concludes, is implausible. Speakers and assessors do not fall for the appearance of paradox with regard to other, standard, features of the index, or circumstances of evaluation, such as world and time.

\section{Generalizing the Challenge: Error in Pragmatic Invariantist Accounts}

A popular strategy for classical invariantists is to explain the variability of acceptance and rejection of knowledge ascriptions that makes for the basic evidence in favor of Contextualism by appeal to general pragmatic mechanisms (see chapters 16-18). Brown (2006) and Rysiew (2001, 2007), among others, pursue this strategy for moderate invariantists who need to explain, among other things, why speakers in HIGH are prone to reject knowledge ascriptions and to accept knowledge denials. Put simply, these invariantists argue that an utterance of "S knows that $\mathrm{p}$ " in a context of utterance pragmatically implicates, rather than semantically expresses, that $S$ is in a good enough position to meet the epistemic standards operative in the context. Hence, an utterance of "S knows that p" in HIGH may semantically express something true but pragmatically implicate a falsehood when $S$ is in a good enough position to meet the invariant moderate epistemic standard but not the contextually determined high standard. 26

What is important to note is that this pragmatic strategy is designed to mimic the predictions of a Contextualist semantics. In consequence, the strategy is faced with (some of) the Contextualist's recalcitrant data. As Kindermann (2016) argues, pragmatic invariantists cannot account for sceptical paradox or retraction data without attributing an implausible form of speaker error. ${ }^{27}$ Therefore, appeals to pragmatic mechanisms are no alternative to error attributions; they incur their very own versions of error objections.

$\S \S 16-17$ served to illustrate by way of two examples that every extant view of the meaning and use of knowledge ascriptions is faced with the attribution of some error to speakers. If this is right, then the dialectical playing field is somewhat levelled. What is needed is, first, a more careful comparison of the kinds of attributed error and a thorough investigation of the criteria that render one error attribution 
plausible and another implausible; and second, a view's error attributions need to be substantiated by plausible psychological accounts that explain why the error occurs systematically in just those use situations for which the view must attribute it. Some such accounts have been sketched on behalf of invariantist accounts. We will take a look at these before closing.

\section{Psychological Error Theories}

Another popular invariantist strategy to explain (away) the intuitive, 'erroneous' judgments not supported by their semantics appeals to some general cognitive mechanism, which interferes with semantic processing and for which we have independent empirical evidence. Hawthorne (2004), for instance, sketches a psychological error theory on behalf of subject-sensitive invariantism. He appeals to a general-purpose heuristic underlying many judgments under uncertainty: Psychological research on heuristics and biases shows that in our probability and frequency judgments we use a small number of heuristics that are cognitively effective, often lead to correct judgments but equally result in biases that may skew our judgments. One such heuristic is the psychological 'availability' of relevant events: In assessing the probability or frequency of an event, we sometimes rely on the ease with which instances of the type can be brought to mind (cf. e.g. Tversky 1973). Similarly, Speakers ascribing knowledge in HIGH, to whom certain error possibilities become salient, or 'available,' tend to pessimistically overestimate the knowledge-destroying danger of these error possibilities and as a result come to deny knowledge. Moreover, Hawthorne claims, they tend to project their overestimations of these error possibilities onto the subject's position and come to also deny knowledge of the subject. Thus, reliance on the availability heuristic in assessing the epistemic danger of non-knowledge-destroying error possibilities may lead to erroneous judgments; attributors in HIGH are pessimistically biased.

Others have developed similar psychological explanations to help moderate insensitive invariantism explain the data. Williamson (2005) also appeals to the availability heuristic. Nagel's Nagel (2008, 2010, 2010a) account draws on the bias called 'epistemic egocentrism'; and Gerken Nagel (2008, 2010, 2010a) develops his epistemic focal bias account within the framework of dual process theories. 30

Whatever the merits of these accounts, invariantists' attempts to integrate epistemological work on knowledge-that with empirical results from cognitive science are clearly moving the debate in the right direction. Existing attributions of linguistic ignorance and error - such as Contextualists' error 
attributions-do not involve a psychological account of how and why speakers deviate from correct use. Invariantists' psychological error theories can claim to deliver just this kind of explanation.

It is worth noting that it is open to Contextualists to co-opt the psychological strategy and explain error in terms of more general cognitive mechanisms. These mechanisms may interfere with the proper execution of semantic competence under certain conditions, leading to systematic errors. On this strategy, then, Contextualists may argue that speakers' semantic competence with "knows" itself is flawless, but that it is skewed under certain conditions by general psychological processes that are not inherently semantic.

\section{Conclusion}

The Semantic Error Problem for epistemic Contextualism comes in the form of different kinds of error objections, from observations about different facts about ordinary speakers' and philosophers' use of knowledge ascriptions. Contextualism's need to attribute semantic error to speakers to account for some use data is seen by some opponents as constituting a decisive objection (e.g. Schiffer 1996); to some proponents, it's further evidence in favor of Contextualism (Schaffer \& Szabo 2014). Here, we haven't taken a definite stance on the force of the Semantic Error Problem for Contextualism. Our main goal has been to chart the different versions of error objections and available responses for Contextualists and to introduce a number of useful distinctions between error attributions as well as different kinds of semantic ignorance and error. Our discussion should serve to highlight two underappreciated points. First, error objections are ubiquitous in the debate about knowledge ascriptions. None of the major extant views accounts for all the use facts without any special pleading. Second, error objections are best understood as challenges to Contextualism, and other views, to provide an error theory - a substantial psychological explanation of why speakers systematically, in particular kinds of situations, use knowledge ascriptions in ways that diverge from the semantics' predictions. So the force of error objections against Contextualism ultimately depends on whether Contextualism has a better explanation of the use data that is erroneous given a Contextualist semantics than other views' explanations of the use data that is erroneous given their semantics.

Given the ubiquity of error objections, the debate does and will benefit greatly from two developments: First, a more systematic comparison and evaluation of different views' needed error attributions (as attempted, e.g., in Kindermann 2012). Second, the development of psychologically substantial error theories that explain some given error rather than merely describe it (cf. §18). 


\section{Bibliography:}

Åkerman, J. \& Greenough, P. (2010). “Vagueness and Non-indexical Contextualism.” In: Sawyer, S. (ed.). New Waves in Philosophy of Language. New York: Palgrave, 8-23

Bach, K. (2005. “The Emperor's New 'Knows'.” In: Preyer, G. and Peter, G. (eds.): Contextualism in Philosophy: Knowledge, Meaning, and Truth. Oxford: Oxford University Press, 51-89

Blome-Tillmann, M. (2008). “The Indexicality of 'Knowledge'.” Philosophical Studies 138(1), 2953

Blome-Tillmann, M. (2009). “Contextualism, Subject-Sensitive Invariantism, and the Interaction of 'Knowledge'-Ascriptions with Modal and Temporal Operators." Philosophy and Phenomenological Research 79(2), 315-31

Blome-Tillmann (2013). “Knowledge and Implicatures.” Synthese 190(18), 4293-4319

Blome-Tillmann, M. (2014). Knowledge and Presuppositions. Oxford: Oxford University Press

Brown, J. (2006). “Contextualism and Warranted Assertibility Manoeuvres.” Philosophical Studies 130(3), 407-35

Cohen, S. (1987). "Knowledge, Context, and Social Standards." Synthese 73(1), 3-26

Cohen, S. (1999). “Contextualism, Skepticism, and the Structure of Reasons.” Noûs 33, 57-89

Cohen, S. (2004). “Contextualism and Unhappy-Face Solutions: Reply to Schiffer.” Philosophical Studies 119(1), 185-97

Cohen, S. (2004a). "Knowledge, Assertion, and Practical Reasoning." Philosophical Issues, 482-91 Cohen, S. (2005). “Contextualism Defended.” In: Steup, M. and Sosa, E.: Contemporary Debates in Epistemology. Malden, MA: Blackwell, 56-62

Conee, E. (2005). “Contextualism Contested.” In: Steup, M. and Sosa, E.: Contemporary Debates in Epistemology. Malden, MA: Blackwell, 47-56

Davis, W. “Are Knowledge Claims Indexical?” Erkenntnis 61(2), 257-81

DeRose, K. (1995). “Solving the Skeptical Problem.” The Philosophical Review 104(1), 1-52

DeRose, K. (1999). “Contextualism: An Explanation and Defense.” In: Greco, J. and Sosa, E. (eds.): The Blackwell Guide to Epistemology. Oxford: Blackwell, 187-205

DeRose, K. (2006). “'Bamboozled by Our Own Words': Semantic Blindness and Some Arguments Against Contextualism." Philosophy and Phenomenological Research 73(2), 316-38

DeRose, K. (2009). The Case for Contextualism. Oxford: Oxford University Press

Dimmock, P. \& Huvenes, T. T. (2014). “Knowledge, Conservatism, and Pragmatics.” Synthese 191(14), 3239-3269 
Fantl, J. and McGrath, M. (2009). Knowledge in an Uncertain World. Oxford: Oxford University Press

Feldman, R. (1999). “Contextualism and Skepticism.” Noûs 33, 91-114.

Gerken, M. (2012). “On the Cognitive Bases of Knowledge Ascriptions.” In: Brown, J. and Gerken, M. (eds.): Knowledge Ascriptions. Oxford: Oxford University Press, 140-70

Gerken, M. (2013). “Epistemic Focal Bias.” Australasian Journal of Philosophy 91(1), 41-61

Goldman, A., 1976, "Discrimination and Perceptual Knowledge”, The Journal of Philosophy, 73: 771-791. Reprinted in Goldman, A. 1992, Liaisons: Philosophy Meets the Cognitive and Social Sciences, Cambridge, MA: The MIT Press, 85-103

Greenough, P. (2011). "Truth-Relativism, Norm-Relativism, and Assertion.” In: Brown, J. and Cappelen, H. (eds.): Assertion. Oxford: Oxford University Press, 197-231

Hawthorne, J. (2004). Knowledge and Lotteries. Oxford: Oxford University Press Ichikawa, J. (2011). “Quantifiers, Knowledge, and Counterfactuals.” Philosophy and Phenomenological Research 82(2), 287-313

Kindermann, D. (2012). "Perspective in Context. Relative, Truth, Knowledge, and the First Person." PhD Dissertation, University of St Andrews

Kindermann, D. (2013). “Relativism, Sceptical Paradox, and Semantic Blindness.” Philosophical Studies 162(3), 585-603

Kindermann, D. (2016). “Knowledge, Pragmatics, and Error”. Grazer Philosophische Studien 93, 429-57

Kölbel, M. (2009). “The Evidence for Relativism.” Synthese 166(2), 375-95

Lewis, D. (1996). “Elusive Knowledge.” Australasian Journal of Philosophy 74(4), 549-67

Ludlow, P. (2005). “Contextualism and the New Linguistic Turn in Epistemology.” In: Preyer, G. \& Peter, G. (eds.). Contextualism in Philosophy: Knowledge, Meaning, and Truth. Oxford: Oxford University Press, 11-50

MacFarlane, J. (2005). “The Assessment-Sensitivity of Knowledge Attributions.” In: Gendler, T.S. and Hawthorne, J. (eds.). Oxford Studies in Epistemology I, Oxford: Oxford University Press, 197-233

MacFarlane, J. (2009) 'Nonindexical Contextualism', Synthese, 166, pp. 231-250.

MacFarlane, J. (2014). Assessment-Sensitivity. Relative Truth and Its Applications. Oxford: Oxford University Press

McKenna, R. (2013). “Epistemic Contextualism: A Normative Approach.” Pacific Philosophical Quarterly 94(1), 101-23 
Montminy, M. (2009). “Contextualism, Relativism, and Ordinary Speakers' Judgments.”

Philosophical Studies 143(3), 341-56

Nagel, J. (2008). "Knowledge Ascriptions and the Psychological Consequences of Changing

Stakes." Australasian Journal of Philosophy 86(2), 279-94

Nagel, J. (2010). “Knowledge Ascriptions and the Psychological Consequences of Thinking about Error." The Philosophical Quarterly 60(239), 286-306

Nagel, J. (2010a). "Epistemic Anxiety and Adaptive Invariantism." Philosophical Perspectives 24, 407-35

Neta, R. (2003). “Skepticism, Contextualism, and Semantic Self-Knowledge.” Philosophy and

Phenomenological Research 67, 396-411

Richard, M. (2008). When Truth Gives Out. Oxford: Oxford University Press

Rysiew, P. (2001). “The Context-Sensitivity of Knowledge Attributions.” Noûs 35(4), 477-514.

Rysiew, P. (2007). "Speaking of Knowing." Noûs 41(4), 627-62

Schaffer, J. (2004). “From Contextualism to Contrastivism.” Philosophical Studies 119(1), 73-103

Schaffer, J. (2004a). "Skepticism, Contextualism, and Discrimination." Philosophy and Phenomenological Research 69(1), 138-55

Schaffer, J. \& Szabó, Z. Gendler (2014). “Epistemic Comparativism: A Contextualist Semantics for Knowledge Ascriptions." Philosophical Studies 168(2), 491-543

Stanley, J. (2004). “On the Linguistic Basis for Contextualism.” Philosophical Studies 119, 119-46

Stanley, J. (2005). Knowledge and Practical Interests. Oxford: Oxford University Press

Stine, Gail C., 1976, "Skepticism, Relevant Alternatives, and Deductive Closure”. Philosophical Studies 29, 249-61

Tversky, A. and Kahneman, D. (1973). Availability: a Heuristic for Judging Frequency and Probability. Cognitive Psychology 5: 207-32

Williamson, T. (2005). "Contextualism, Subject-Sensitive Invariantism, and Knowledge of Knowledge." The Philosophical Quarterly 55(219), 213-35

Blome-Tillmann (2008, 2009, 2014), Cohen (1987, 1999, 2004, 2004a, 2005), DeRose (1995, 1996, 2006, 2009), Goldman (1976), Ichikawa (2011), Lewis (1996), Neta (2003), McKenna (2013), Schaffer (2004, 2004a), Schaffer \& Szabo (2014), Stine (1976), and others.

"Semantic error has hitherto been called "semantic blindness". However, a blind person's visual apparatus works in ways that produce (some degree of) lack of visual information (relative to a norm), rather than in the delivery of misinformation. This, we'll argue, is in contrast to the semantic case. Moreover, since semantic error is apt to be seen as a bad thing, the use of "semantic blindness" runs the risk of being an ableist metaphor. 
${ }^{3}$ Various (related) problems are found in: Bach (2005), Conee (2005), Davis (2004), Feldman (1999), Hawthorne (2004), MacFarlane (2005), Schiffer (1996), Stanley (2004, 2005), and Williamson (2005).

. Contextualism is here neutral between Indexical Contextualism and Non-Indexical Contextualism. The former entails that there to be a difference in proposition expressed across contexts of use, while the latter holds that the content of "S knows that $\mathrm{p}$ " is invariant but can be true relative to one set of epistemic standards and false relative to another. See MacFarlane (2009).

"That's controversial if evidence is constituted by, e.g., what one knows (see Williamson 2000), but nothing turns on this issue below.

See Schaffer \& Szábo (2014) for a form of Modest Contextualism.

Here, we do not intend to commit to a view of semantic competence in terms of (implicit) beliefs about the semantic properties of expressions in the language. Talk of (implicit) belief is simply picked as one way to conceptualize, e.g., the difference between semantic ignorance and error.

Cf. MacFarlane 2005, 215.

See Stine (1976), Cohen (1988), DeRose (1995), Lewis (1996).

"Here we outline what DeRose (1995) calls the "scepticism-friendly" version of Contextualism.

"One forceful reason: it would be an "abominable conjunction", in both LOW and HIGH, to assert: I know that O but I don't know that not-SH (DeRose 1995, §7).

12 We take such a semantic story to subsume the meta-semantic story as to why the salience of error produces a high-standards context, and the non-salience of error produces a low-standards context.

${ }^{13}$ Cf. Schiffer (1996).

"Schiffer also considers two further implementations of Indexical Contextualism. The first treats

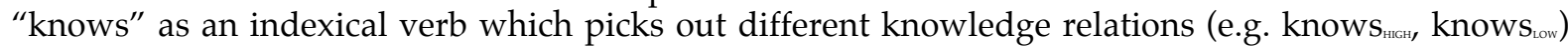
in different contexts. He thinks this does no better than hidden-indexical Contextualism (p. 327). The second appeals to the idea that "knows that" is vague, plus the idea that such vagueness entails that the penumbra/extension of "knows that", like that of "flat", can vary with the standards operative in the context of use (pp. 327-8). While Schiffer finds such variability plausible, he alleges that it will not help since we are "perfectly aware when it is going on". So, again, Contextualism cannot accommodate the kind of error theory needed.

${ }^{15}$ Here we adapt DeRose (2006, pp. 333-336) who instead uses judgments as to whether those who assert and those who deny Premise A (or indeed C) are genuinely disagreeing.

${ }^{10}$ Moderate invariantism is the view that "S knows that $\mathrm{p}$ " is not relevantly context-sensitive and that subjects are able to meet the epistemic conditions for knowing.

"See, for instance, the work on psychological error theories in Nagel (2008, 2010, 2010a), Gerken (2013), and a systematic comparison of the main contenders' error ascriptions in Kindermann (2012).

is Schaffer \& Szabo (2014) continue: "Indeed we suspect that those who endorse the transparency premise must ultimately be the sort of radical invariantists who only allow for context sensitivity with core indexicals and demonstratives." See also Blome-Tillmann (2014, 107-110) against transparency.

"Similarly, Hawthorne (2004,104-07) argues that if "knows that" was context-sensitive in a way similar to that of gradable adjectives ("empty, "flat"), then speakers should be able to avail themselves of "clarification" techniques to state more precisely what they meant. A speaker who asserts "That is flat" and is then challenged with "Well, it's got a few small holes in it" would be able to clarify what she meant by saying, e.g., "All I meant is that it is flat for a football field". But no such natural linguistic devices of clarification seem available in the case of knowledge ascriptions. According to Hawthorne, the theorist's locution "relative to high standards" is not a natural clarification device speakers have in their repertoire. (Though see Ludlow (2005) for a list of natural language expressions which are in use with knowledge ascriptions and may count as clarification devices.) MacFarlane (2005, section 2.3) puts the articulation/clarification point in the context of retraction: I will retract rather than reformulate / articulate my previous knowledge ascription in a way to show it consistent with my current claims. See also Feldman (2001, p. 74, pp. 78-9).

${ }^{20}$ MacFarlane (2014, 180-1) makes this point specifically against Contextualism. Cf. Conee 2005.

"A more specific self-undermining objection concerns a tension in Schiffer's $(1996,326-7)$ local semantic error objection: With respect to the sceptical paradox, he claims that (i) a speaker interprets the proposition in the conclusion $\mathrm{C}$ as false and the proposition expressed by Premise A as true; and (ii) yet she is "totally ignorant of the sort of thing she's saying" because she can't articulate it. But note that in order to have strong intuitive judgments of truth and falsity, the speaker must have determinate if implicit views of what is said. If she was "totally ignorant" of which proposition the conclusion expresses, she would be at a loss in evaluating it for truth and falsity. 
2 The broad worry also besets Non-Indexical Contextualism.

${ }^{2}$ Richard (2008) and Kölbel (2009) also endorse relativism about knowledge ascriptions. See also chapters 22 ("Contextualism, Relativism, and the Problem of Disagreement") and 23 ("Epistemological Implications of Relativism").

${ }^{2}$ Cf. the notion of "Content-Blindness" in Kindermann (2013).

${ }^{25}$ Cf. Akerman and Greenough (2009) on the distinction between (Strong and Weak) Content Blindness and (Strong and Weak) Truth Blindness.

${ }^{26}$ Cf. Greenough (2011) who advocates Norm-Relativism - a form of Invariantism under which there is demanding norm of assertion in HIGH (assessment contexts), and a less demanding norm of assertion in LOW (assessment contexts). Unlike the various competitor forms of Invariantism such a view can handle retraction data (without succumbing to relativism about truth).

"See also Dimmock \& Huvenes 2014.

» See also chapter 7, "The Psychological Context of Contextualism", by Nagel \& Smith. 